\title{
Hypnotherapy and the power of the mind
}

\section{Abstract}

In the mind our life stories are stored, which directs our lives. Hypnosis is a tool to access that part of our mind at will. Through hypnotherapy we can tap into the subconscious mind where all suppressed issues reside, resolve them and create long lasting changes. By resolving these suppressed memories/issues we unleash the power of our mind in order to create the life we desire.

"If you want to heal the body, you must first heal the mind." Plato
Volume 3 Issue 2 - 2016

\author{
Debbie Papadakis \\ Hypno Healing Istitute INC, Canada
}

Correspondence: Debbie Papadakis, Hypno Healing Istitute INC, 355 Keele Strret, Toronto, Ontario M6P-2K6, Canada, Tel 416-760-8996, Email Debbie@hypno-healing

Received: October 01, 2015 | Published: February 15, 2016

\section{Mini review}

Have you evaluated your life to see how satisfied you are with your results? Are there any areas in your life such as relationships, finances, health, work, that are unsatisfactory and you wonder why? Are you sabotaging yourself or are you cultivating your dreams and desires? How much time have you invested in getting to know your mind's autonomous processes and intricate mechanisms? Your answers are directly correlated with the quality of your life.

Wisdom lies in mastering the mind. To fully grasp the extensive power of your mind to create your desires, we need to treat the mind as a self-feeding and self-realized independent entity. Through intention, one is fully capable of designing the reality of his/her choice. The mind functions on three different levels: the conscious, the subconscious and the unconscious.

The conscious mind is the part of the mind that is responsible for all the analytical, rational information, the short-term memory and also the thinking and questioning. The conscious enables us to assimilate an assortment of tasks and form logical conclusions.

The subconscious mind is the one that holds all the emotions, beliefs, self-image and experiences. It is associated with long term memory. The subconscious is usually programmed, voluntarily or involuntarily, by our primary caregivers, society, culture, and religion. Even though we are not aware of our subconscious mind, it is always present and influences our behaviors in our daily lives.

The unconscious mind is the domain of the automatic bodily functioning of our being, for example, blinking your eyes happens automatically without having to think about it. The unconscious mind is affected by the emotions we hold in the subconscious. We operate in "default mode" or on "automatic pilot". If you find yourself in a state of agitation it can have a direct impact on the physical function of your body.

As you can see, the majority of the mind's activity takes place in the subconscious and unconscious mind. Examining the depths of our mind is crucial for shedding light on that which drives us or triggers us in certain life situations.

To recognize the big part that our mind plays in our lives, we need to understand the power of the mind. First of all, all parts of the mind are valuable and dynamic. Our self-image is stored in the mind, and the strongest idea most individuals struggle with is the sensation of 'I am'. The 'I am' feeling, or as the philosopher Alan Watts calls it: "The skin encapsulated ego', is simply a mind concept, that all of us were forced to adopt in early childhood, in order to be integrated in the family and be a part of the surrounding community. The 'I am' construct is built upon a series of subconscious patterns, which determine one's individuality, thus the ability to self-express.

In order to resolve some of our deeper issues we need to release the 'but', voice of the conscious mind and explore what's behind it in the subconscious mind.

At a conscious level, many human beings diligently work towards joy, health, fulfillment and abundance; subconsciously, however, they may carry inside scarcity, unresolved trauma, emotional blockages, and mental bondages. At a cellular level, our DNA records karmic residues, generational messages, past life experiences, unresolved emotions and all forms of data we have unknowingly absorbed in our childhood years. The conscious mind is heavily influenced, positively or negatively by the incredible amount of information stored in the subconscious mind.

The first step of a profound personal transformation lies in communicating with your subconscious. As I mentioned earlier the subconscious holds all the root cause of issues. As long as individuals continue to treat the symptoms of their emotional and physical issues or illnesses, but not the root cause, they will find themselves baffled by a vicious cycle. Let us take the example of someone struggling with food addiction. The individual might consciously choose to eat healthy and to exercise more; in the best case scenario, the compulsive eater will manage to stick to his new routine for a short time until some emotional issue appears. In most cases the individual will readopt their usual habits and fall into the old patterns.

This is because intensive emotional, mental and physical treatments require diving into the shadowy aspects of the persona which is stored at the subconscious levels. One of the ways to access and work with the subconscious is to use Hypnotherapy.

Hypnosis is often misrepresented as a state of unconsciousness, a trance in which the person is asleep and unaware of what is happening. It is a state of focused attention, heightened state of awareness accompanied by an increased insight to one's inner processes.

Hypnotherapy has been approved by the British Medical Association in 1955, by the American Medical Association in 1958 and has been incorporated with psychotherapy since the earliest days of its existence. Dr. Milton H. Erickson was an American psychiatrist who specialized in medical hypnosis and family therapy. He contributed to the major shift in modern psychotherapy. In 1957, Dr. Erickson and a number of colleagues founded the American Society of Clinical Hypnosis. However, despite this, it remains an approach that is strongly debated and that is seen as lacking effectiveness or being 
used as a parlor trick. Despite these misconceptions, hypnotherapy remains a popular and effective method for working with behavioral changes and emotional conflicts with long lasting results.

Hypnosis is a therapeutic tool that can directly access the subconscious mind and bypasses the critical part of the conscious mind. At the conscious level, it can be hard to access the oldest and emotionally significant experiences that individuals have had, because the conscious mind stands in the way. It can be a way to protect the individual from remembering and reliving negative emotions and unpleasant memories, however, it can also prevent the person from overcoming those memories and traumatic experiences. By using hypnotherapeutic and psychotherapeutic techniques, the root of the problem can be accessed directly and resolved.

Through the guidance of a Hypnotherapist, using psychotherapeutic and hypnotherapeutic techniques, the client is able to trace the root cause of their issue back to the original traumatic event in their existence that hinders them from moving forward.

For example, I worked with a client who craved sweets constantly. I traced the craving back to a childhood event. When the client was only 5years old she witnessed other children eating sweets. Her father said they had no money to buy sweets. She felt sad and cried during that part of the session. By looking at the event with an adult comprehension she is able to let go of the sadness, scarcity, replace it with fulfilled desires, satisfied feelings and gain a true understanding of the situation. We brought her back to the current time while replacing all the negative feelings, beliefs and emotions that were associated and effected by that event with the new and positive, happy and satisfied feelings, knowing that she could have all the desserts she desired whenever she wanted them. Weeks later she shared that the chronic urges for having sweets were gone.

Another example, is someone struggling with self-worth issues. When working with the primary trauma, the client is guided to the root cause of the issue and once the initial trauma that caused him/her to feel less or undeserving is resolved, the client embraces the path of self-love and acceptance shifting their perspective from thoughts like: "I am not good enough", "Nobody loves me", "Life is pointless" to "I am love", "I am worthy", "I am liberated". It is imperative to resolve the painful event that caused the feeling; otherwise working on this issue from a conscious level is futile.

Hypnotherapy broadens the horizons of the client, by assisting $\mathrm{him} / \mathrm{her}$ in releasing the baggage of their own past experiences and influences. Once embarked on the journey towards the self, the client comes into contact with their inborn potential. This infinite potential of growth and co-creation remains the same throughout one's human experience. The access key to unlock the stream of conscious creation is to shed light on the unconscious and subconscious constraints we were born with or that we have accumulated during our life. Once light flows in the dimension of our shadowy aspects, our perception is cleansed and we can radiantly enter through the opened gates of celebration and fulfillment.

There is evidence to prove the effectiveness of hypnosis. In a series of studies done over the years, it was seen that hypnotherapy could help with a wide variety of health issues. It was found to have a positive effect on asthma, arthritis, bone fractures, pain, irritable bowel syndrome and headaches, among others. ${ }^{1-6}$ It was found to help women in childbirth ${ }^{7}$ and with reducing the experiences of pain. ${ }^{8}$ It also was connected to better and faster healing, as well as to an improved recovery after surgery. Hypnosis was also useful for individuals who wanted to quit smoking (Elkins \& Rajab, 2004). As for mental health issues, there is evidence to support the effectiveness of hypnosis for depression among other issues. ${ }^{9}$

Hypnosis can tap into the power of the mind, referring to the deep aspects of the unconscious mind that can have a great effect on both minds and bodies. It can connect more directly to the inner power of healing that is inherent to humans, but that may be blocked by conscious beliefs, doubts and ideas. It is a direct way of reaching to the conflict, bypassing those aspects that have a negative effect on a person's ability to resolve their emotional blockages.

Hypnotherapy is experiencing resurgence at the moment, as more studies show that it is effective. There are schools and centers devoted to the study and teaching of hypnotherapy, as well as treatment of patients.

Hypnotherapy, in conclusion, is an accepted therapeutic tool that can be used to release suppressed emotions and deal with conflicts on a deep level, reaching for the root of the problem. It can activate the power of the mind and bring the individual's resources to work on the problem, which can be reflected in physical or emotional healing.

\section{Acknowledgments}

None.

\section{Conflicts of interest}

Author declares there are no conflicts of interest.

\section{Funding}

None.

\section{References}

1. Anderson JA, Basker MA, Dalton R. Migraine and Hypnotherapy. International Journal of Clinical and Experimental Hypnosis. 1975;23(1):48-58.

2. Domangue BB, Margolis CG, Lieberman D, et al.Biochemical Correlates of Hypnoanalgesia in Arthritic Pain Patients. Journal of Clinical Psychiatry. 1985;46(6):235-238.

3. Ginandes CS, Rosenthal DI. Using hypnosis to accelerate the healing of bone fractures: a randomized controlled pilot study. Altern Ther Health Med. 1999;5(2):67-75.

4. Hammond DC. Review of the efficacy of clinical hypnosis with headaches and migraines. Int J Clin Exp Hypn. 2000;55(2):207-219.

5. Maher-Loughnan GP. Hypnosis and AutoHypnosis for the Treatment of Asthma. Int J Clin Exp Hypn. 1970;18(1):1-14.

6. Whorwell PJ, Prior A, Colgan SM. Hypnotherapy in Severe Irritable Bowel Syndrome: Further Experience. Gut. 1987;28(4):423-425.

7. Harmon TM, Hynan M, Tyre TE. Improved obstetric outcomes using hypnotic analgesia and skill mastery combined with childbirth education. J Consult Clin Psychol. 1990;58(5):525-530.

8. Elkins GR, Rajab MH. Clinical hypnosis for Smoking Cessation: preliminary results of a three session intervention. Int J Clin Exp Hypn. 2004;52(1): 3-81

9. Alladin A, Alibhai A. Cognitive hypnotherapy for depression: an empirical investigation. Int J Clin Exp Hypn. 2007;55 (2):147-166. 